\title{
Gamma-ray attenuation for measuring cryogenic slush mixture density
}

\author{
A. Carapelle *, J.-P. Collette \\ Centre Spatial de Liège, University of Liege, Avenue du Pré-Aily, B-4031 Angleur-Liège, Belgium \\ Received 9 June 2004; received in revised form 14 September 2004
}

\begin{abstract}
Gamma-ray attenuation is used to measure cryogenic mixture density. Parameters are optimized for specific space application. A simple error formula is established. The feasibility of the measurement is demonstrated. An automatic measurement device is built.
\end{abstract}

(c) 2004 Elsevier B.V. All rights reserved.

PACS: $29.30 . \mathrm{Kv} ; 81.70 .-\mathrm{q}$

Keywords: Slush mixture; Density; Gamma-ray attenuation

\section{Introduction}

In the frame of the European Space Agency (ESA) activities, previous study [1] shows that replacing liquid hydrogen by cryogenic solid-liquid mixture (slush mixture) of hydrogen can reduce the launcher mass up to $26 \%$. An important parameter of this slush mixture is the solid fraction. It can be obtained by measuring the density of the mixture. This work shows the density measurement of cryogenic slush mixture by the atten\footnotetext{
5613

${ }^{*}$ Corresponding author. Tel.: +32 4367 6668; fax: +324 367

E-mail address: a.carapelle@ulg.ac.be (A. Carapelle).
}

uation of $\gamma$-rays. Densitometers using $\gamma$-rays attenuation are well known and has been adapted to special applications [2] but none of them have been used to measure cryogenic slush mixture. The aim of this work is to demonstrate the ability of cryogenic measurement of slush mixture and to build an automatic densitometer.

\section{Measurement principle}

The density measurement is based on the wellknown Lambert law:

$I=I_{0} \cdot \mathrm{e}^{-\mu_{\mathrm{M}} \cdot \rho \cdot x}$.

With the classical geometry described in Fig. 1. 


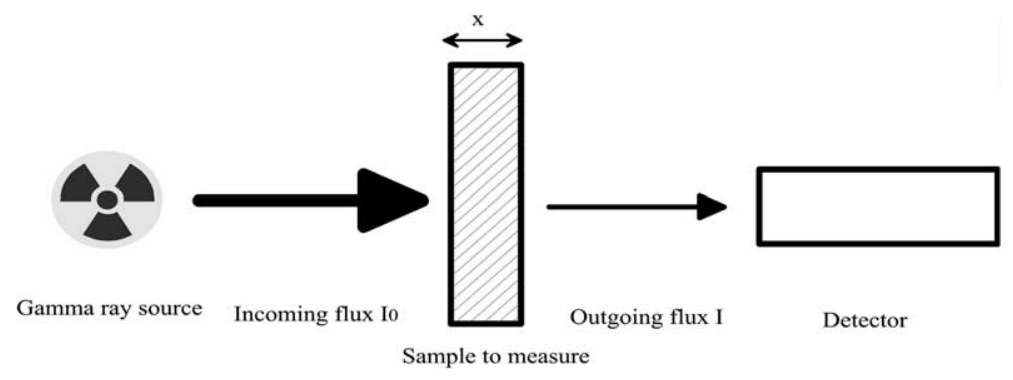

Fig. 1. Measurement principle.

Where $I_{0}$ and $I$ are incoming and outgoing $\gamma$-ray flux, $\rho$ the density of the sample, $x$ the length of the sample and $\mu_{\mathrm{M}}$ the mass absorption coefficient. $\mu_{\mathrm{M}}$ can be obtained by using XCOM software from the NIST [3].

The density is then given by

$\rho=\frac{-1}{\mu_{\mathrm{M}} \cdot x} \ln \left(\frac{I}{I_{0}}\right)$.

We also need the error on the measured density. $I$ and $I_{0}$ are found by pulse counting, and for high count rates the statistical error on $I$ and $I_{0}$ are respectively $(I)^{1 / 2}$ and $\left(I_{0}\right)^{1 / 2}$. If we neglect the error on $\mu_{\mathrm{M}}$ parameter, we can use the propagation error formula [4] to obtain the relative error on density:

$\frac{\Delta \rho}{\rho}=\frac{\Delta x}{x}+\frac{\frac{1}{\sqrt{I}}-\frac{1}{\sqrt{I_{0}}}}{\ln \left(\frac{I}{I_{0}}\right)}$.

Eq. (1) can be re-written $I=c \cdot I_{0}$ where $c=$ $\mathrm{e}^{-\mu_{\mathrm{M}} \cdot \rho \cdot x}$, thus Eq. (3) becomes

$\frac{\Delta \rho}{\rho}=\frac{\Delta x}{x}+\frac{\frac{1}{\sqrt{c \cdot I_{0}}}-\frac{1}{\sqrt{I_{0}}}}{\ln (c)}$,

the relative error on $\rho$ can be re-written

$\frac{\Delta \rho}{\rho}=\frac{\Delta x}{x}+\frac{c^{\prime}}{\sqrt{I_{0}}}$,

with

$c^{\prime}=\frac{1-\sqrt{\mathrm{e}^{-\mu_{\mathrm{M}} \cdot \rho \cdot x}}}{-\mu_{\mathrm{M}} \cdot \rho \cdot x \cdot \sqrt{\mathrm{e}^{-\mu_{\mathrm{M}} \cdot \rho \cdot x}}}$.
From Eq. (5), we see that the relative error can be reduced by increasing $I_{0}$, it can be done by increasing the $\gamma$-rays source activity and/or measurement time.

From Eq. (6), we see that the relative error is a function of $x, \rho$ and $\mu_{\mathrm{M}} . x$ is a characteristic of the experimental set-up and cannot easily be adjusted. $\rho$ is the parameter to measure and cannot be adjusted. Nevertheless, it is interesting to look at the evolution of the relative error on density as a function of the density. Fig. 2 shows the evolution of relative error as a function of the density in the case of nitrogen with our particular experimental set-up.

Eq. (6) shows that relative error on density is also a function of $\mu_{\mathrm{M}}$ parameter.

Fig. 3 shows the evolution of relative error on $\rho$ versus $\mu_{\mathrm{M}}$ parameter.

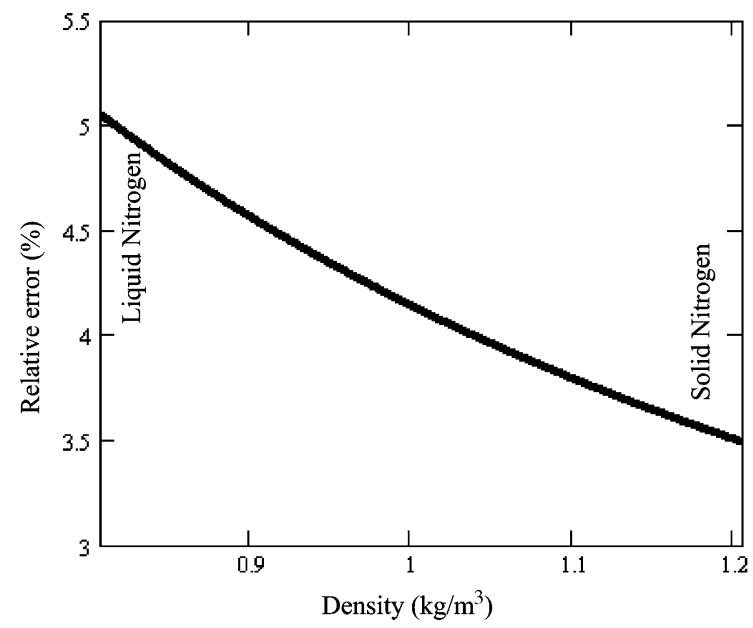

Fig. 2. Relative error on density versus density. 


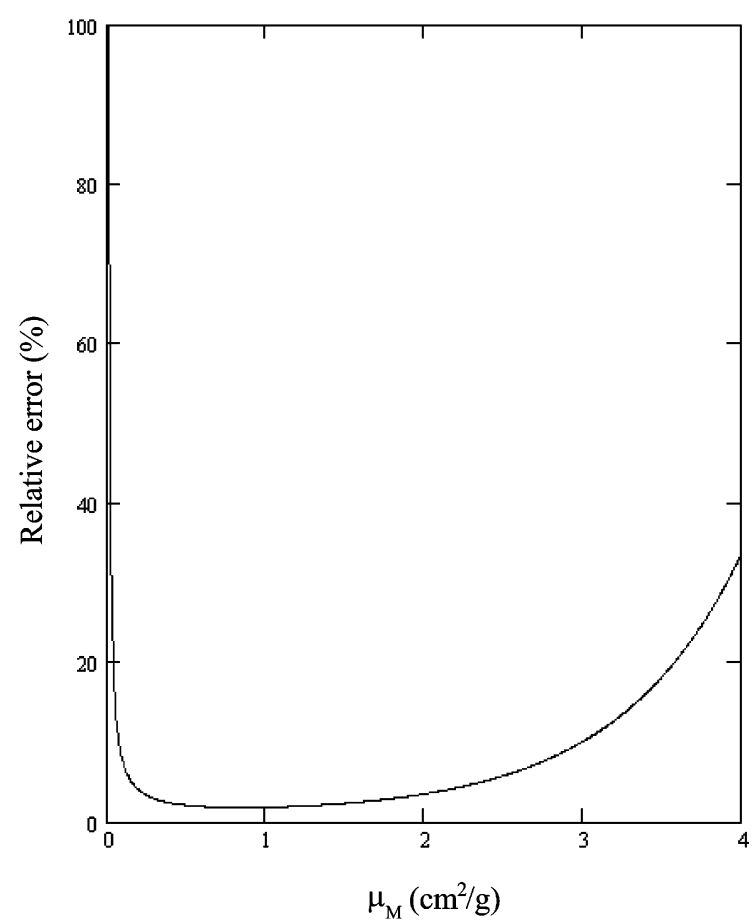

Fig. 3. Relative error on density versus $\mu_{\mathrm{M}}$ parameter.

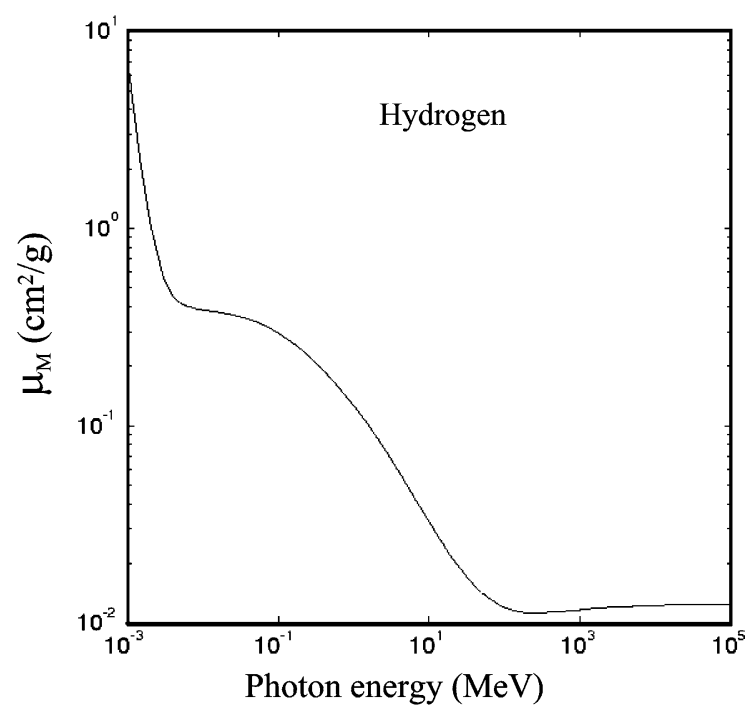

Fig. 4. $\mu_{\mathrm{M}}$ parameters as a function of $\gamma$-rays energy in the case of hydrogen.

As one can see, the relative error on density decreases as $\mu_{\mathrm{M}}$ parameter decreases. But for very small value of $\mu_{\mathrm{M}}$ parameter, the relative error on density increases rapidly as $\mu_{\mathrm{M}}$ parameter decreases. Practically, it is a good idea to have $\mu_{\mathrm{M}}$ as small as possible but to keep it greater than $0.1 \mathrm{~cm}^{2} / \mathrm{g}$. For a given sample of a given density, $\mu_{\mathrm{M}}$ parameter only varies with the energy of $\gamma$ rays. Fig. 4 shows the evolution of $\mu_{\mathrm{M}}$ parameteras a function of the energy of $\gamma$-rays in the case of hydrogen [3].

If we want small value for $\mu_{\mathrm{M}}$ but greater than $0.1 \mathrm{~cm}^{2} / \mathrm{g}$, we see that we must use $\gamma$-rays with energy between 0.1 and $1 \mathrm{MeV}$.

\section{Experimental results}

The experimental set-up used is a classical $\gamma$ spectroscopy set-up. It is composed of a $\gamma$-rays source, a NaI crystal detector, a photo-multiplier tube (PM), a pre-amplifier (NaI, PM and preamplifier are combined by using an Ortec 296 Scintipak), an amplifier, a multichannel analyzer (MCA, Amplifier and MCA are combined in a Canberra Series 20 Multichannel Analyzer) and a computer that uses a spectroscopy analyzis software [5]. The $\gamma$-rays source is a sealed ${ }^{137} \mathrm{Cs}$ source of about $5 \mu \mathrm{Ci}$. We choose ${ }^{137} \mathrm{Cs}$ because it has one main $\gamma$ emission at $662 \mathrm{keV}$. This energy is in the $0.1-1 \mathrm{MeV}$ range and is therefore suitable.

The analyzis software is used to count how many $\gamma$ photons are in the $662 \mathrm{keV}$ peak of the ${ }^{137} \mathrm{Cs}$. This ensures that $\gamma$ photons which undergo Compton effect, and do not go in straight line, are not counted (because their energy is modified).

The $\gamma$-ray flux is collimated to pass through the sample. After the sample, the NaI crystal detects the remaining flux. Fig. 5 shows the experimental set-up, the electronic read-out to be considered in this case is the classical $\gamma$-rays spectroscopy set-up.

The $x$ parameters used in Eqs. (1) and (2) can not be measured directly because the slush production facility has a complicated geometry. This parameter is then calculated by using the following equation, coming directly from Eq. (1):

$$
x=\frac{-1}{\mu_{\mathrm{M}} \cdot \rho} \ln \left(\frac{I}{I_{0}}\right) .
$$




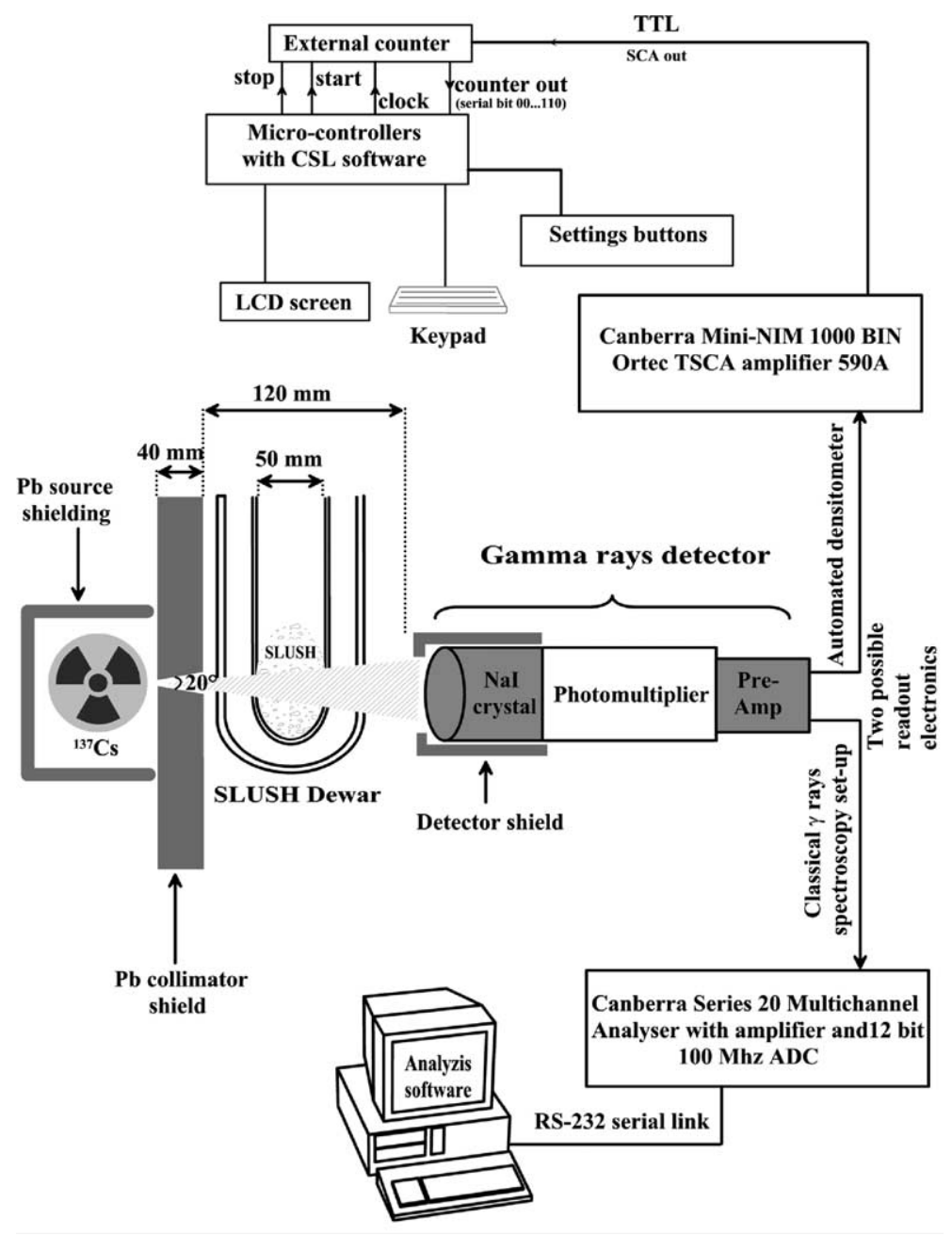

Fig. 5. Experimental set-up.

We calculate $x$ with Eq. (7) with a fluid of known density (water or liquid nitrogen) and the equation for the relative error on $x$ can be obtain by the propagation error formula [4], the relative error on $x$ is then given by

$$
\frac{\Delta x}{x}=\frac{\frac{1}{\sqrt{I}}-\frac{1}{\sqrt{I_{0}}}}{\ln \left(\frac{I}{I_{0}}\right)} .
$$

For our particular set-up, we obtain $1.94 \mathrm{~cm} \pm$ $3.3 \%$ for the $x$ parameter, these value is calculated using Eqs. (7) and (8).
Eq. (2) is then used to calculate density of measured liquid. The $I_{0}$ parameter is measured by pulse counting with an empty dewar. The $I$ parameter is measured by pulse counting with a dewar full of fluid to be measured.

Table 1 shows the results of measured density for different liquids at room temperature.

Table 2 shows the results of measured density of different liquids at cryogenic temperature.

Fig. 6 shows the result of density measurement on nitrogen slush melting down. Fig. 7 shows the result of density measurement on neon slush melting down. 
Table 1

\begin{tabular}{llll}
\hline Material & $\begin{array}{l}\text { Density measured } \\
\left(\times 10^{3} \mathrm{~kg} / \mathrm{m}^{3}\right)\end{array}$ & $\begin{array}{l}\text { Tabulated density } \\
\left(\times 10^{3} \mathrm{~kg} / \mathrm{m}^{3}\right)\end{array}$ & $\begin{array}{l}\text { Difference }(\%) \\
\text { (with account to absolute error) }\end{array}$ \\
\hline $\mathrm{H}_{2} \mathrm{O}_{2}(17 \%)$ diluted hydrogen peroxide & $(1.180 \pm 0.059)$ & 1.090 & 2.84 \\
Acetone & $(0.909 \pm 0.045)$ & 0.792 & 9.09 \\
Chloroform & $(1.51 \pm 0.0755)$ & 1.489 & 0 \\
\hline
\end{tabular}

Table 2

\begin{tabular}{lccl}
\hline Material & $\begin{array}{l}\text { Density measured } \\
\left(\mathrm{kg} / \mathrm{m}^{3}\right)\end{array}$ & $\begin{array}{l}\text { Theoretical density } \\
\left(\mathrm{kg} / \mathrm{m}^{3}\right)\end{array}$ & $\begin{array}{l}\text { Difference }(\%) \\
\text { (with account to absolute error) }\end{array}$ \\
\hline $\begin{array}{l}\text { Liquid nitrogen at triple point } \\
\text { Liquid neon at triple point }\end{array}$ & $\begin{array}{c}(811 \pm 41) \\
(1210.7 \pm 35)\end{array}$ & $\begin{array}{c}808 \\
0\end{array}$ \\
\hline
\end{tabular}

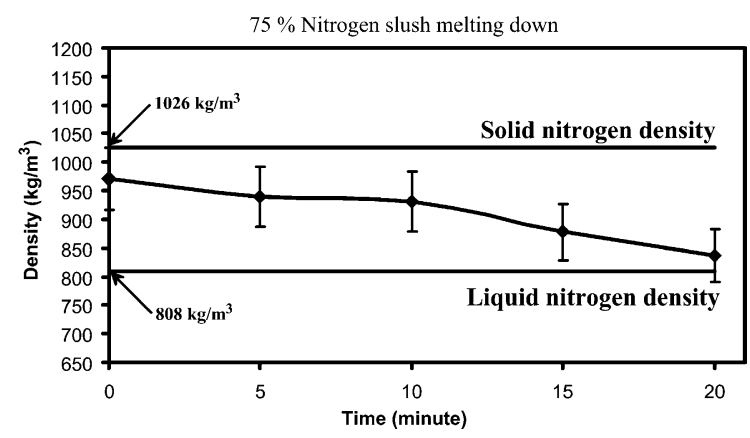

Fig. 6. Density measurement on nitrogen slush melting down.

Our slush production facility is not mechanically stable and can be misaligned during measurement, this could explain measurement after $20 \mathrm{~min}$ of neon slush melting down.

For safety reasons, tests are carried on neon and nitrogen but not on hydrogen.

\section{Automated device design}

If the densitometer is used in future space launcher, it must be automatic. For this reason, we have designed an automatic densitometer based on the same principle. The main difference is that we replaced the MCA by a single channel analyzer (SCA) whose window is surrounding the ${ }^{137} \mathrm{Cs}$ $662 \mathrm{keV}$ peak. The SCA output provides a TTL

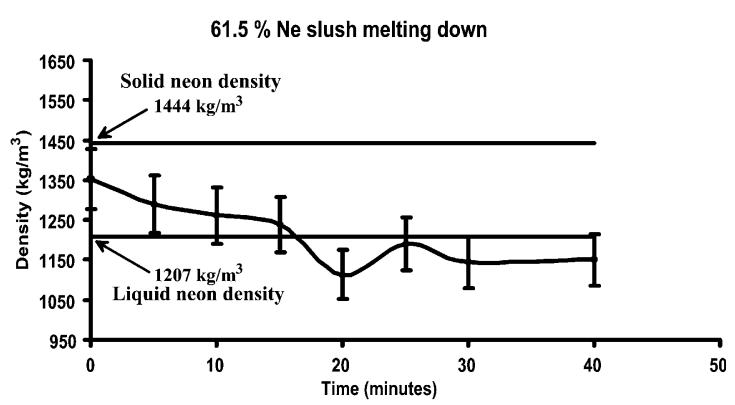

Fig. 7. Density measurement on neon slush melting down.

positive signal when a $\gamma$ photon of the good energy is detected. The TTL signal reaches a counter coupled to a micro-controller. The micro-controller software uses Eqs. (2) and (6) to calculate density and its relative error. The result is displayed on a LCD screen. Fig. 5 shows the design of the automated densitometer, the electronic read-out to be considered in this case is automated densitometer.

Tests on liquid and slush nitrogen show that the results displayed by the automated densitometer are correct. The automated densitometer is used by Magna Steyr (Austria) to characterize the slush produce in large quantity in their slush production facility. Magna Steyr is currently producing nitrogen slush and is planning to upgrade the facility to produce hydrogen slush in the near future. Table 3 shows some results of measurements of nitrogen slush produced by Magna Steyr. 
Table 3

\begin{tabular}{lll}
\hline Sample description & $\begin{array}{l}\text { Measured density } \\
\left(\times 10^{3} \mathrm{~kg} / \mathrm{m}^{3}\right)\end{array}$ & $\begin{array}{l}\text { Statistical relative error } \\
\text { (including error on } x \text { parameter) }\end{array}$ \\
\hline Liquid nitrogen (LN2) & 0.770 & $\pm 6.05 \%$ \\
Liquid nitrogen at triple point & 0.810 & $\pm 5.88 \%$ \\
Slush nitrogen (SLN2) & 0.840 & $\pm 5.8 \%$ \\
Slush nitrogen (SLN2) & 0.850 & $\pm 5.77 \%$ \\
\hline
\end{tabular}

\section{Conclusions}

We establish a simple theory for error on density measurement using $\gamma$-rays attenuation. We show that $\gamma$-rays attenuation is suitable for measuring density of cryogenic slush mixture. We built an automated densitometer that can be used for space application.

\section{Acknowledgements}

This work is funded by ESA and Belgian SSTC services.

The authors wish to thanks Nuclear Physic Institute (IPNAS) of the University of Liege for their technical help.

\section{References}

[1] SDP FESTIP phase 1 Heat Management final presentation, ESA, April 1997.

[2] S.-A. Tujgum, J. Frieling, G.A. Johansen, Nucl. Instr. and Meth. B 197 (2002) 301.

[3] M.J. Berger, J.H. Hubbell, NBSIR 87-3597, XCOM: Photon cross sections on a personal computer, National Institute of Standards and Technology, Gaithersburg, MD 20899, USA, 1987.

[4] European co-operation for Accreditation, Expression of the Uncertainty of Measurement in Calibration, Publication Reference EA-4/02, 1999.

[5] P.-H. Lefèbvre, M. Clar, H.-P. Garnir, in: D. Bulfone, A. Daneels (Eds.), Proceedings of the 7th International Conference on Accelerator and Large Experimental Physics Control Systems, Trieste, Italy, 1999, p. 567. 